\section{Collagenous Duodenitis and Collagenous Colitis: A Short Clinical Course as Evidenced by Sequential Endoscopic and Histologic Findings}

A 25-year-old male patient complained of mucoid, watery and nonbloody diarrhea for 4 weeks. Stool volumes and frequency (520 per day) varied. Furthermore, he suffered from cramping abdominal pain and weight loss of $10 \mathrm{~kg}$. Physical examination was normal except for the patient's fatigued appearance.

The white blood cell count was $14500 / \mu 1$. The hemogram showed $74.4 \%$ neutrophils, $10.5 \%$ lymphocytes, $10.6 \%$ monocytes, $3.0 \%$ eosinophils, and $0.4 \%$ basophils. Stool studies for infectious etiologies were unremarkable.

The initial esophagogastroduodenoscopy revealed signs of gastritis, and colonoscopy showed colitis with erosive-ulcerative lesions. Histopathological investigation demonstrated a reactive gastritis with no sign of Helicobacter pylori, while the mucosa of the colon presented inflammatory alterations reminiscent of a resolving infectious colitis. Focal subepithelial collagen fiber deposits were suggestive of a possible transition to collagenous colitis (Figure 1).

The patient was treated with antibiotics (metronidazole, mezlozillin), an antiinflammatory agent (mesalazine, Salofalk) and an $\mathrm{H}_{2}$-receptor antagonist.

The frequency of bowel movements remained almost unchanged for 3-4 weeks. Subsequent endoscopy revealed signs of an erosive antral gastritis and duodenitis (Fig-

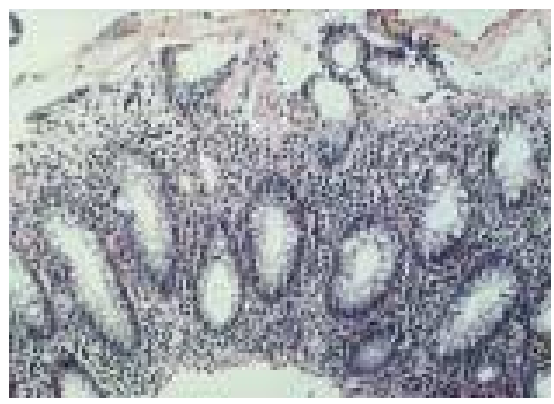

Figure 1 Moderate infiltration of the colonic mucosa by lymphocytes, plasma cells, and polymorphonuclear leucocytes, with epithelial regeneration and focal deposits of collagen fibers in the center (van Gieson; × 200)
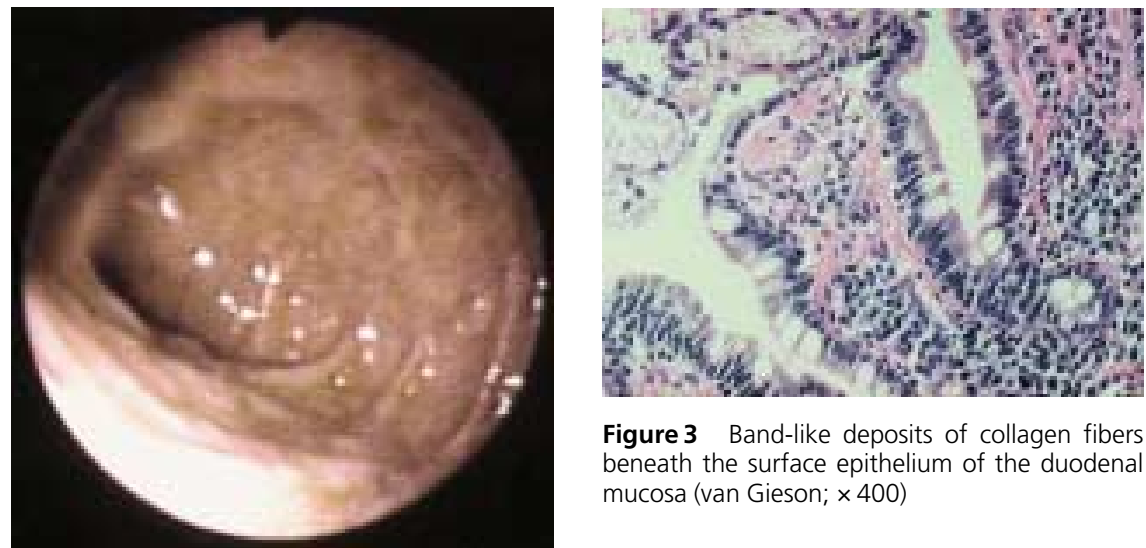

Figure 3 Band-like deposits of collagen fibers beneath the surface epithelium of the duodenal mucosa (van Gieson; × 400)

Figure 2 Duodenitis with minor mucosal changes

ure 2). The colonic ulcerations were no longer detectable. Instead only discrete inflammatory changes were found in the ascending colon. The biopsies obtained at this point clearly disclosed a pattern consistent with collagenous duodenitis (Figure 3) and collagenous colitis.

Further therapy consisted of mesalazin (Salofalk). The patient was symptom-free after 2 months of treatment. At 9 months after the diagnosis had been made, the clinical, laboratory, endoscopic, and histologic findings revealed complete remission.

Collagenous duodenitis is a rare disease with only seven cases reported in the literature. Each of those cases involved additional regions of the gastrointestinal tract [1-7]. The current (eighth) case report is the first to show that various affected regions of the intestine displayed simultaneous complete remission with the same treatment. The collagenous duodenitis and collagenous colitis healed after 9 months. Both diseases might reflect a similar or identical entity.

\section{F. S. Schreiber ${ }^{1}$, S. Eidt ${ }^{2}$, M. Hidding ${ }^{3}$,}

J. Schmidt-Walczuch ${ }^{1}, C$. Werning ${ }^{1}$

${ }^{1}$ Dept. of Medicine,

St. Katharinen Teaching Hospital,

University of Cologne Medical School,

Frechen, Germany

${ }^{2}$ Institute of Pathology,

St. Elisabeth Teaching Hospital,

University of Cologne Medical School,

Cologne, Germany

${ }^{3}$ Institute of Forensic Medicine,

University of Cologne Medical School,

Cologne, Germany

\section{References}

${ }^{1}$ Eckstein RP, Dowsett JF, Riley JW. Collagenous enterocolitis: a case of collagenous colitis with involvement of the small intestine. Am J Gastroenterol 1988; 83: 767-771

${ }^{2}$ Borchard F, Niederau C. Collagenous gastroduodenitis. Dtsch Med Wochenschr 1989; 114: 1345

${ }^{3}$ Stolte M, Ritter M, Borchard F, et al. Collagenous gastroduodenitis on collagenous colitis. Endoscopy 1990; 22: 186-187

${ }^{4}$ Meier PN, Otto P, Ritter M, et al. Collagenous duodenitis and ileitis in a patient with collagenous colitis. Leber Magen Darm 1991; 21: 231-232

${ }^{5}$ McCashland TM, Donovan JP, Strobach RS, et al. Collagenous enterocolitis: a manifestation of gluten-sensitive enteropathy. J Clin Gastroenterol 1992; 15: 45-51

${ }^{6}$ Chatti S, Haouet S, Ourghi H, et al. Collagenous enterocolitis. Case report and review of the literature. Arch Anat Cytol Pathol 1994; 42: 149-153

${ }^{7}$ Castellano VM, Muñoz MT, Nevado M, et al. Collagenous gastrobulbitis and collagenous colitis. Scand J Gastroenterol 1999; 6: 632-638

Corresponding Author

F. S. Schreiber, M.D.

Gastroenterology Division 600A C.R.B.

University of Pennsylvania

415 Curie Blvd.

Philadelphia, PA 19104

USA

Fax: $\quad+1-215-573-2024$

E-mail: franzs@mail.med.upenn.edu 